Original Article Journal of ocial Research and Behavioral Sciences

Received/Accepted Dates

15.10.2021/15.11.2021

DOI

10.52096/jsrbs.6.1.7.13.35
Sosyal Araştırmalar ve Davranış Bilimleri Dergisi

ISSN:2149-178X

Volume: 7 Issue: 13 Year: 2021

\title{
Sosyal Ağlarda Çokkültürlülük Üzerine İnceleme: Youtube Tepki Videoları
}

\section{Cansu YÜCEL}

İstanbul Üniversitesi Sosyal Bilimler Enstitüsü

Radyo Televizyon ve Sinema Ana Bilim Dalı

Yüksek Lisans Öğrencisi

yucel_cansu@hotmail.com

\author{
Doç. Dr. Ümit SARI \\ İstanbul Üniversitesi İletişim Fakültesi \\ Radyo Televizyon ve Sinema Bölümü \\ umitsari@istanbul.edu.tr
}

\section{Özet}

Coğrafi ve kültürel alanda sınırların ortadan kalkması, uluslararası alanda hareketliliğin ve bilgi akışının hızlanması ile özelikle 20. yüzyılda sıkça karşımıza çıkan küreselleşmenin getirdiği en önemli kavramlardan biri çokkültürlülüktür. Irkçılığı ve ayrımc1lı̆̆g önleme, farklılıklara karşı hoşgörü ve duyarlılığ1 arttırma ve kültürlerarası etkileşim sağlama ideallerine sahip çokkültürlülük kavramı, günümüz dünyasının geldiği noktada farklı bir boyuta taşınmıştır. Çokkültürlülük, kültürel inşa süreçlerinin gerçekleşmesine olanak tanıyan bir alan olarak internet ortamlarında anlam kazanarak kültürel süreçlere hizmet eder. Çalışma, çokkültürlülük kavramının devlet politikaları düzeyindeki tanımının yanında dijital alandaki tanımının yapılabilmesine katkı sağlamayı hedefler. Bu doğrultuda dünya genelinde en çok kullanılan sosyal ağlardan biri olan YouTube üzerinden örneklerle çokkültürlülüğe sağlanan katkının ortaya 
konması amaçlanmıştır. YouTube'da, farklı kültürden bir kullanıcının Türk müzik videolarını izleyerek verdiği tepkileri içeren kanal ve bu kanaldan örneklerle içerik analizi yöntemi kullanılarak incelenmiştir.

Anahtar Kelimeler: Sosyal Bilimler, Sosyal Ağlar, Küreselleşme, Çokkültürlülük, YouTube

\title{
Analysis of Social Networks on Multiculturalism: Youtube Reaction Videos
}

\begin{abstract}
Multiculturalism is one of the most important concepts brought about by the disappearance of borders in the geographical and cultural areas, the acceleration of mobility and information flow in the international arena, and especially in the 20th century. The concept of multiculturalism, which has the ideals of preventing racism and discrimination, increasing tolerance and sensitivity towards differences and providing intercultural interaction, has been moved to a different dimension at the point where today's world has come. Multiculturalism serves cultural processes by gaining meaning in internet environments as a field that allows cultural construction processes to take place. The study aims to contribute to the definition of the concept of multiculturalism at the level of state policies as well as its definition in the digital field. In this direction, it is aimed to reveal the contribution of multiculturalism with examples via YouTube, one of the most used social networks worldwide. On YouTube, the channel containing the reactions of a user of different cultures by watching Turkish music videos and examples from this channel were analyzed using content analysis method.
\end{abstract}

Structured Abstract: The most common interpretation of globalization is the idea that the world has become more homogeneous and standardized through a technological, commercial and cultural synchronization spreading from the West, and that globalization is connected with modernity. Globalization, which is frequently discussed today, is a comprehensive concept that is based on geographical discoveries and extends to the state it has taken under the influence of today's technological developments. In today's world, globalization has turned into a way of life and has become the normal of our daily lives. Globalization in general; the disappearance of national borders, allowing the free movement of goods, services and cultures around the world. Robertson says that globalization is centered around two main orientations. While the first refers to economic interdependence, the other refers to the globalization of institutions, communities and practices (2013: 136).

Globalization includes several dimensions. The cultural dimension is among the most important of these. The cultural dimension of globalization can be considered within the scope of transportation, 


\section{Sosyal Ağlarda Çokkülttürlülü̈k Üzerine İnceleme: Youtube Tepki Videoları}

communication and communication as a result of its economic basis. The fact that different parts of the world are in contact with economic purposes has allowed different cultures to get to know each other, and cultures that include small groups to be noticed. Intercultural interaction has reached a high level with digital communication channels.

The cultural dimension of globalization has led to the emergence of various concepts. Multiculturalism is one of these concepts. Multiculturalism, as a system of thought, defines the fair promotion of different cultures in the public sphere and the peaceful coexistence of different cultural communities within the same political organization (Dotycheva, 2009:12).

In the digital age we live in, every field has a multicultural structure. The fact that communication tools enable universal communication has led to the emergence of social networks. The borderless structure of social networks directly serves multiculturalism.

Youtube, chosen as the subject of analysis of the study, is a social network that is visited and content is produced by millions of people around the world. Cultural content is also produced on YouTube, where all kinds of videos can be shared. It allows a culture to introduce itself and spread it from various aspects. It does this effectively with the power of visuality. By accessing the content on this network from all over the world, it is possible to watch videos, obtain information, give feedback and contribute to the expansion of the content by producing.

YouTube's "Kingdom of Luke" channel, chosen as the field of study, shows its experiences about different cultures by watching music clips from different countries. While creating content, it does a preliminary research about the video to watch instead of just watching. Considering the five videos selected as a sample, $60 \%$ of the videos explain the content and give information about the song. It gives information about the song genre in $40 \%$ of the videos. Explains the musical genres that have their own characteristics as "anthem" and "folk song" and indicates their characteristics. The channel owner gives information about the singers in $100 \%$ of the videos. Explain what kind of music the singers make, their life, their place and importance in Turkish music. In this way, he gets information about the culture he is foreign to through the artists. It gives historical information on $60 \%$ of the pieces.

The channel owner makes inferences about culture in $60 \%$ of the videos he examines. All of these videos are pieces with historical content. He states that as a result of his viewing experience, he was influenced by pieces with historical content and shared a sense of victory and struggle. This shows that even though it is experienced by different societies, all world rights can develop common feelings in situations such as war, destruction and victory. There are Turkish and English comments in all of the videos and in the comments under the video. This shows that besides being watched by users from Turkey, it is watched by different 
cultures or that users use the universal language English to appeal to all cultures. Thanks to the video content, a content producer from a different culture gained knowledge as a result of his researches and impressions about the culture he is foreign to; It has made them accessible to millions of people by publishing them on the most used video sharing site all over the world. Many people had the opportunity to access this video, and those who watched the content had the opportunity to have information about Turkish culture. These contents, which contribute to the multicultural structure in the digital field, contribute to the empathy of different cultures with each other and to develop positive thoughts about culture; It emphasizes love and respect by preventing racism and discrimination.

Keywords: Social Sciences, Social Networks, Globalization, Multiculturalism, YouTube

\section{Giriş}

İnsanoğlunun varoluşundan, özellikle topluluklar halinde yaşamaya başladığı en erken dönemlerine uzanarak kültür kavramından söz edilmeye başlanabilir. Topluluk halinde yaşamın getirdiği davranış biçimleri ve düşünce kalıpları insanları bunlara ortak olmaya, tekrarlamaya itmiştir. İnsanların bir araya gelerek oluşturduğu kültür, daha sonra onun topluluklar halinde yaşayabilmesini sağlayan bir döngü yaratmıştır. Uyum sağlayarak, grubun bir parçası olarak yaşama ihtiyacı süregelmiştir. İnsanın varlığıyla bütünleşik bir olgu olarak kültür; kapsamı geniş, tanımlaması zor ve farklı düşünce sistemleri tarafından farklı şekillerde ele alınabilen bir kavramdır. Türk Dil Kurumu sözlüğünde kültürün tanımı "tarihsel, toplumsal gelişme süreci içinde yaratılan bütün maddi ve manevi değerler ile bunları yaratmada, sonraki nesillere iletmede kullanılan, insanın doğal ve toplumsal çevresine egemenliğinin ölçüsünü gösteren araçların bütünü” (URL 1) olarak yapılır.

İşlemek, yetiştirmek, düzenlemek, inşa etmek anlamlarına gelen Latince "colere" fiilinden türetilen "cullura" terimi ilk kez 16. Yüzyılda tarımsal faaliyetlere ilişkin kullanılmış bir kavramdır. "Kültür" kavramının tarımsal anlamdaki bu temel anlamı daha sonradan insanın işlenmesi, eğitilmesi, zihnin yetiştirilmesi anlamlarında kullanılmıştır (Thompson'dan akt. Ay, 2017: 5). 18. Yüzyıla kadar tekil anlamında kullanılan bu kültür tanımının, modern anlamda ikincil düzeyde tanımları mevcuttur. Bu tanım zihinsel, manevi ve estetik alana dair bağımsız bir kavramı, belirli bir yaşam biçimini tanımlayan bir kavramı ve entelektüel ürünleri ve uygulamaları 
tanımlayan soyut bir kavramı içerir (Sarı'dan akt. 2017: 6). Toplumsal yaşamın tarihsel süreç içinde giderek büyüyen dönüşümü kültürün tanımını da bireyden toplumsal olana doğru dönüştürmüştür. Kültürün gelişimi ve dönüşümü onun yaşayan ve dinamik bir kavram olduğunun göstergesidir. Tarihsel süreç içindeki toplumsal dönüşümler kültürel gelişimlerin en önemli sebebidir. Toplumsal olaylar, keşifler, icatlar kültür üzerinde etki bırakarak onun gelişimine olanak tanımıştır. Çeşitli sebeplerle birbirlerine temas eden toplumlar karşılıklı etkileşimler ve alışverişlere imkan vermiş̧ir.

Kültür üzerine yapılan çalışmalarda değinilmesi gereken en önemli kavramlardan biri kimliktir. Kültürle benzer şekilde kimlik de yaşayan ve dinamik bir kavramdır. 60'11 yllarda kültürel kimliklerin keşfi için çalışmalar yaparak kimlik politikalarının gelişmesini sağlayan Kellner; daha önceden kimliklerin aile, din, meslek, ideoloji gibi kavramlar ışığında yapıldığını ancak günümüz medya çağında kimlik tanımlarının değişerek feminist, muhafazakâr, gay, çevreci gibi toplumsal hareketlerin ortaya çıkardığı figürleri ile şekillendiğini ifade etmiştir. (akt. 2017: 9). Kültürel kimliklerin geçirdiği bu değişimin en önemli etkenlerinin başında küreselleşme gelmektedir.

18. Yüzyılda Sanayi Devriminin etkisiyle ekonomik ve teknolojik alanda yaşanan gelişmeler; buhar makinesinin deniz ve demiryolu ulaşımında kullanılmaya başlanması, yeni üretim tekniklerinin gelişmesiyle malların hızla üretilip ulaştırılmasını sağlayan ekonomik süreç, o dönemde adı konulmasa da bir küreselleşme sürecine işaret etmektedir. Bunun yanında 20. Yüzyılın ortalarından itibaren iletişim alanında yaşanan önemli gelişmeler ile kültürlerarası ilişkilerin ileri düzeyde gerçekleşmesini sağlayarak küreselleşmenin gelişimine katkı sağlamıştır. Kapalı toplumların sınırlarının aşıldığı bir dönemde kültürlerarası etkileşimler de kaçınılmaz ve doğal bir olgu haline gelmiştir. (Mahiroğulları 2010:1276-1279).

\section{Çokkülttürlülüğe Giden Yol: Küreselleşme}

Küreselleşmenin en yaygın yorumu dünyanın Batı'dan yayılan teknolojik, ticari ve kültürel bir senkronizasyon yoluyla daha homojen ve standart bir hale geldiği ve küreselleşmenin modernite ile bağlandığı fikridir. Pieterse, dar bir değerlendirme olarak bu yorumların her ikisini de ele alarak küreselleşmeyi bir melezleşme süreci olarak görmeyi savunur (Pieterse, 2006: 658). 
Pek çok araştırmacı küreselleşme sürecini hem ticaret hem de kültürel etkileşim bağlamında 15 . Yüzyılın sonlarındaki coğrafi keşiflere dayandırır. Küreselleşmenin başlıca kuramcılarından olan Giddens, bu kavramı "uzak yerleşimleri birbirlerine, yerel oluşumların millerce ötedeki olaylarlabiçimlendirildiği ya da bunun tam tersinin söz konusu olduğu yollarla bağlayandünya çapındaki toplumsal ilişkilerin yoğunlaşması" şeklinde tanımlamaktadır (Giddens, 1994: 62). Ayrıca yine Giddens'a göre küreselleşme tekdüze bir süreçten ziyade karmaşık süreçlerin bir arada toplandığı bir olgular kümesidir (Aydeniz, 2012: 1016). Küreselleşmeye getirdiği tanımda Giddens kavramın uzak yerellikleri birbirine bağlama ve dünya çapındaki toplumsal ilişkileri pekiştiren bir modernite olduğu özelliğini de vurgulamıştır (Aydoğan, 2011: 5). 18. yüzyılda Sanayi Devrimi'nin mal, hizmetler, ulaşım, taşımacılık ve haberleşme alanındaki gelişmeleriyle küresel anlamda bir dönüşüm süreci yaşanırken; sömürgecilik faaliyetlerine girişen Batılı ülkeler misyonerlik faaliyetlerine başvurarak kültürel anlamda küreselleşmeyi de gerçekleştirmişlerdir. Öncelikle sınır ötesi ticaret bağlamında ekonomik boyutuyla ortaya çıkan kavram, sonraki yıllarda siyasal, sosyal ve kültürel yapıları da etkisi altına almıştır (Mahiroğulları 2010:1276-1278). Bugünkü bildiğimiz anlamda küreselleşme ise İkinci Dünya Savaşı bitiminde ABD öncülüğünde ortaya çıkan IMF, Dünya Bankası, WTO, WHO, UNESCO gibi örgütlenmelere dayanır (Güllüdağ, 2013:138). Tüm bu gelişmelerle dünya küresel bir pazar haline gelmiş, kültürler arasındaki duvarlar zamanla yıkılmış, kaynaşmalar olagelmiştir. Teknolojik gelişmeler; özellikle dijitalleşme, küreselleşme kavramını başka boyuta taşıyan bir basamak olmuştur.

Günümüzde sıkça ele alınan küreselleşme, temelde coğrafi keşiflere dayandırılarak, günümüz teknolojik gelişmelerinin etkisiyle aldığı hale değin uzanan kapsamlı bir kavramdır. Günümüz dünyasında küreselleşme yaşam biçimine dönüşmüş, gündelik hayatımızın normali olmuştur. Genel anlamıyla küreselleşme; ulusal sınırların ortadan kalkarak mal, hizmet ve kültürlerin dünya genelinde serbest dolaşımına olanak sağlamasını ifade eder. Robertson, küreselleşmenin iki ana yönelim etrafında toplandığını söyler. Bunlardan ilki ekonomik anlamdaki karşılıklı bağımlılığa gönderme yaparken diğeri kurumların, toplulukları ve pratiklerin küreselleşmesine gönderme yapar (akt.2013: 136).

Sermayenin paylaşım ve dolaşım dinamikleri küreselleşen dünya düzeninin ekonomik boyutunu oluşturmaktadır. Amaç bir sermaye merkezinden çevreye doğru yayılan bir akışı döngüsel hale getirmektir. Ticari sözleşmeler, gümrükler, uluslararası anlaşmalar ve topluluklar buna kanıt 
olarak gösterilebilir. Küreselleşmenin ekonomik tanımı, her türlü denetimden uzak; devletin özel teşebbüsün yararları için düzenlendiği ve yönlendirildiği uygulamaları içeren neoliberalizmdir. Neoliberal politikaların uygulanabilmesi için ulus üstü kurumların devreye girmesi gerekmektedir (2013: 141-142).

Küreselleşmenin kültürel boyutu, ekonomik temelinin bir getirisi olarak ulaşım, haberleşme ve iletişim kapsamında ele alınabilir. Kültürel küreselleşme; fiziksel, enformatik ve sanal anlamda ülkeler arasındaki duvarlar yıkılırken birbiriyle teması hızlanan kültürler arasındaki etkileşimler sonucunda kültürlerin iç içe girmesi ve dünya çapında özellikle Amerikan ve Batı kültürleri bağlamında kültürel bir homojenleşme sürecidir (Adıgüzel, 2011: 132). Dünyanın farklı noktalarının ekonomik amaçlarla temas halinde oluşu farklı kültürlerin birbirini tanımasına, küçük grupları kapsayan kültürlerin fark edilmesine olanak sağlamıştır. Dijital iletişim kanalları ile de kültürler arası etkileşim üst düzeye ulaşmıştır. Küreselleşen dünyanın getirdiği anlayış ile küresel çapta kültürel anlayışların gelişmesine zemin hazırlamıştır. Bunun yanında birçok araştırmacı küreselleşmenin başta Amerika ve Batılı ülkelerin olduğu hakim kültürün, dünya çapında dayatılan bir düzenin geliştiğine dair söylemlerde bulunur.

Küreselleşmenin, dünyanın giderek küçülmesiyle mal ve hizmetlere ucuz ve kolay ulaşım, hızlı haberleşme ve ulaşım, devletlerarası ilişkilerin gelişmesi, kültürlerin birbiriyle tanışıp etkileşimde ve alışverişte bulunması gibi olumlu taraflarının yanında olumsuz yanları da vardır. Sömürgeleştirilen bölgelerin Batılı devletlere bağımlı kalıp ekonomik ve sosyal-politik gelişim gösterememesi, ucuz iş gücü olarak toplumların/grupların kötü şartlarda çalıştırılması, bir kültürün baskın gelerek tek yönlü bir küreselleşmeye sebep olması, diğer gruplara dayatılarak onlar üzerinde kültürel çözülmeye sebep olması, ırkçılık ve nefret gibi problemler sayılabilir.

Tomlinson, karmaşık bağlantıların var olduğu küresel dünyada milyonlarca insanın hatta gezegenin kaderinin birbirine bağlı olduğunu söyler (akt. 2013:137). 2019'un sonlarında Çin'de ortaya çıkıp 2020'de tüm dünyayı saran Koronavirüs salgını bunun en canlı kanıtıdır. Virüs taşıyan belirli sayıdaki insanın dünyanın her yerinden insanlarla birebir temasıyla salgın yayılmıs, bireylerden tüm dünyayı saran küresel bir felakete dönüşmüştür. Ekonomik ve politik tüm işleyişler dünya genelinde aniden değişmiş, eğitim öğretim faaliyetleri durmuş; bilimsel çalışmalar virüsün tedavisi, yayılımının önlenmesi ve küresel etkileri üzerine eğilmiş, tüm dünya aynı anda 
evlerine kapanmak zorunda kalmıştır. Salgının dünyası ulusal sınırların ve kimliklerin var olmadığı bir dünyadır.

\section{Çokkültürlülük}

Küreselleşmenin kültürel alanda getirdiği birçok kavramdan biri çokkültürlülüktür. Küreselleşme gibi yeni bir kavram olsa da geçmişi doğal olarak eskilere dayanır. Politik ve ekonomik ilişkiler, savaşlar, ticaret, göç gibi birçok sebep kültürlerin doğal olarak temas etmesinin yolunu açmış; bazı topluluklar bir arada yaşamayı benimserken bazıları reddederek çatışmalar yaşamıştır. Ancak nihayetinde birçok kültür iç içe geçmiş, günümüzde çokkültürlü toplum yapısı tüm dünyaya hakim olmuştur. Çokkültürlülük bir politika olmanın ötesinde küreselleşen dünyanın doğal toplumsal yapısıdır. Ancak çokkültürlü toplum ile çokkültürcü politikalara sahip toplumlar aynı şeyi ifade etmez.

Çokkültürlülük, bir düşünce sistemi olarak günümüz dünyasında farklı kültürlerin kamusal alanda adil biçimde teşvik edilmesini ve aynı siyasi örgütlenme içinde farklı kültürel toplulukların barışçıl şekilde var olabilmelerini tanımlar (Dotycheva, 2009:12). Farklılıkların siyasal alanda tanınması, konumlandırılması ve takınılan tutumla ilgilidir. Küreselleşmeyle yaşanan gelişmeler, yerel olana verilen önemin artması, iletişimin kültürel etkileri çokkültürlü anlayışın ortaya çıkmasını sağlamıştır. Özellikle II. Dünya Savaşı öncesinde ve esnasında etkili olan milliyetçi anlayışın yıkıcı sonuçları ve sonrasında değişen dünya düzeni ile farklılıklara karşı geliştirilen hoşgörü, çokkültürlü anlayışın gelişiminde etkilidir.

Çokkültürlü toplum ifadesi ilk defa 1950'li yıllarda İsviçre'de anılmıştır (Prato'dan akt. Ay, 2017:55). Çokkültürcü politikalarının ilk ortaya çıkışı ise 1970'lerin başında göç alan ülkeler olan Avustralya ve Kanada'da gerçekleşir. Hükumetlerin yerli halkların ve göçmenlerin kültürel farklılıklarının teşvik edilmesinin benimsendiği politikalar olarak gelişmiştir. Daha sonraki yıllarda öncelikle Amerika, Britanya, Yeni Zelanda sonrasında ise Avrupa ve Latin Amerika'da yayılmıştır. Fransa'da ise tarihi değerlere ters düştüğü düşünülerek çokkültürlülük olumlu karşılanmamıştır (Doythcheva. 2009:12). Bu sistemin ortaya çıkış1 çokkültürlü yaşayan toplumların ihtiyaç duyduğu politikaları karşılamayı amaçlar. Farklı kültürlere dahil bireylerin 
kültürel özelliklerini koruyarak aynı zamanda birer dünya vatandaşı hissiyle yaşamaları hedeflenir. Türkiye'de ise birçok batı ülkesinden çok daha fazla kültürel çeşitlilik olmasına rağmen çokkültürcü uygulamalar çok geç gündeme alınmış ve çalışmalar yeterli nitelikte olmamıştır.

Kanadalı sosyolog Will Kymlicka çokkültürlü anlayışın ortaya çıkışıyla ilgili olarak, Hitler'in yaptığ etnik ve dinsel kıyımın etkisiyle Birleşmiş Milletler bünyesindeki ülkeleri eşitlikçi birtakım politikalara yönlendirdiğinden bahseder. Bunların ilki sömürgesizleştirme mücadelesi, ikincisi siyahi hareketleri olarak başlayıp devam eden ırkçıllğga ve ayrımcıllğa karşı mücadeledir (akt. Ay, 2017:56). Tarihsel gelişim süreci içinde grupların ve bireylerin kültürel kimliğe yönelik taleplerinin arttığı, sosyal ve politik beklentilerinin yükseldiği görülmektedir.

Günümüz dijital egemen çağda, devlet politikalarının ötesinde, her alan çokkültürlü bir yapıya sahiptir. İletişim araçlarının evrensel çapta haberleşmeyi ve etkileşimi mümkün kılması, sosyal ağların dünyanın her yerinden insanın iletişim kurmasına olanak sağlaması global çapta bir çokkültürlülük sağlar. Büyük küçük farketmeksizin her kültürün kendini ifade etmesinin önünün açılmasıyla farklılıklara olan saygı ve özen artmış; dezavantajlı gruplara yönelik gelişen duyarlılık ile ırkçılık, şiddet ve istismara yönelik farkındalık düzeyi yükselmiştir. Hakim kültürün empoze edildiği ana akım medyanın yanında, dünyanın Batı dışında da kültürlerinin olduğunu hatırlatan bir mecra olarak sosyal ağlar kültürü inşa dinamiklerinden biri olmuştur.

\section{Sosyal Ağlar ve Çokkülttürlülük}

1960'lı yıllarda olası bir savaş halinde geleneksel iletişim araçlarıyla haberleşmenin kesilmesi durumunda kullanılması amacıyla, ABD Savunma Bakanlığı bünyesinde "Advanced Research Project Agency", kısaca ARPA, denilen grubun çalışmalarıyla bizi bugünkü anlamda internete ulaştıracak olan bir iletişim ağının temeli atılmıştır. ABD'deki üniversite ve kuruluşların dahil olmasıyla hızla gelişip 80lerin sonlarında yaygınlaşan internet, bireylerin sayısal yayıncı olabildiği devrimsel bir oluşumdur (Akyol, 2014:93). Sayısallaşmanın basit düzeydeki bir teknolojik kurulum olmanın ötesinde günümüzde insan hayatını yönlendiren bir yapısı vardır. Bunu sağlayan en önemli alan sosyal ağlardır. Sosyal ağ terimini ilk kez 1954 yılında kullanan Barnes, söz konusu terimin bireyler arasındaki rastlantısal tanışmalardan ailevi bağlara kadar uzanan ilişkilerin haritası 
olduğunu belirtmişstir (Kuyucu \& Karahisar, 2013: 62). Oluşturduğu içerik ve tasarım ile sosyal ağlar, geniş çapta bir katılım sağlamayı, bireyler arasında yoğun ve anlık etkileşim ile kendine ait bir kültürel alan yaratmayı hedefler. Bireysel olarak kendini ifade etme, aynı düşüncelere sahip kişileri bir araya getirebilme özelliği ile etkileme ve kamuoyu oluşturma gücü vardır. Günümüzde canlı yayın özelliği dahi bulunan sosyal ağlar, geleneksel iletişim araçlarından çok daha hızlı haberleşmeyi sağlar. Sosyal ağlar neoliberal politikaların yayılma aracı olarak kullanılabilmesinin yanında, bir politik sistem olmanın ötesinde dünyanın çokkültürlülüğünü yansıtan ve geliştiren bir mecra olarak karşımıza çıkar.

Sosyal ağ siteleri Web 2.0 ile ortaya çıkan bilgisayar dolayımlı bir türdür. İlk sosyal teknolojiler, benzer ilgi alanları olan insanları bir araya getirme amacı güderken yakın dönem teknolojiler insanları birbirine bağlayarak bununla ortaya çıkacak ilgi alanları üzerine olmuştur. Sosyal ağların bir uzantısı olan "sosyal medya" gündelik hayatın birçok yönünü yansıtmakta, bir yandan da sanal ve gerçek arasındaki sınırları bulanıklaştırmaktadır (Boyd'dan akt. Çizmeci: 2014: 386-388). Sanal ve gerçeğin birbirine geçmesiyle gündelik olan ile "olması istenilen" yer değiştirmiştir. Kendini ifade etme aracı olma özelliğiyle sağladığı olanakların yanında, yarattığı sanal kültür ile insanların davranışlarını değiştirmede etkili olmuştur. Sosyal ağ ile sosyal medya kavramlarının aynı olmadığını savunan görüşler de mevcuttur. Kara'nın Kaplan ve Haenlein'den aktardığına göre sosyal medya; kullanıcı tarafından oluşturulan, içerik üretimine ve paylaşımına olanak veren, Web 2.0'ın ideolojik ve teknolojik temelleri üzerine inşa edilmiş internet tabanlı uygulamalar grubudur (Kara, 2013: 44).

Çokkültürlü alan olarak sosyal medya kültürlerin kendini tanıtmak ve ifade aracı olarak önemli bir konuma sahiptir. Kendi kültürü de dahil olmak üzere bir kültür hakkında bilgi edinmek, etkileşime geçmek isteyen insan sosyal medya aracılığıyla kültür hakkında bilgi edinebilir; bu kültürlere ait insanlarla iletişime geçerek sanal olarak bir araya gelebilir. Bu kültürler tüm dünyaya olumlu izlenim bırakacak şekilde sunularak ırkçılık ve ayrımcılık gibi durumların önüne geçilebilir.

Birçok kültür hakkında bilgi sahibi olan insan, farkındalık seviyesinin artmasıyla farklılıklara karşı saygı duymayı öğrenir. Bu sayede çokkültürlü bireyin inşasında önemli bir rol oynar. Diğer yandan yine medyanın baskın kültürü kendi kültürünü dayatmacı şekilde sunabilir; bunun da ötesinde tahakküm kurmak istediği bir grubu olumsuz ve ayrımcılığa yol açacak şekilde gösterebilir. Sosyal 
medyanın anında geribildirim yapmaya elverişli yapısı buna itiraz edebilmeyi sağlasa da, etkileme gücü nedeniyle birçok insan kolayca yanlış da yönlendirilebilir.

Çalışmanın analiz konusu olarak seçilen Youtube, dünya çapında milyonlarca kişi tarafından ziyaret edilen ve içerik üretilen bir sosyal ağdır. Her türden videonun paylaşılabildiği YouTube'da kültürel içerikler oluşturularak ağa dahil edilebilir. Bir kültürün birçok açıdan kendini tanıtmasına, kendisini cazip kılarak yaymasına, hem de bunu görsel bir biçimde oldukça etkileyici şekilde yapmasına olanak sağlar. Dünyanın her yerinden bu ağdaki içeriklere ulaşarak videoları izlemek, bilgi edinmek, geribildirimde bulunmak, ve üretimde bulunarak içeriğin genişlemesine katlı sağlamak mümkündür.

\section{Youtube}

2005 yılında Chad Hurley, Steve Chen ve Jawad Karim tarafindan Menlo Park'ta bir garajda kurulan YouTube, 2006 yılında Google tarafından satın alındığında aynı zamanda Time dergisi tarafından yılın icadı olarak seçilmiştir (Ying'den akt. Güllüdağ, 2013:257). Kuruluşundan bir yıl sonra Google tarafından satın alınması YouTube'un kısa sürede sağladığı başarıyı gözler önüne sermektedir. İlk video paylaşım sitesi olma özelliğini taşıyan YouTube aynı zamanda bunların en büyüğüdür. Günümüzde de tüm bu özelliklere ek olarak geliştirdiği içerikler ve geldiği konum ile en popüler ağların başındadır.

Basit bir video paylaşma ve izleme sitesi olmanın ötesinde YouTube kişisel profiller oluşturma özelliğiyle kişisel kanalları var eder. Kişisel profil aynı zamanda kişinin kanalını oluşturarak özel alanlara ve farklı gruplara hitap eden içeriklerin bir arada toplanmasını sağlar. Profillerin birbirini takip etmesiyle dileyen kişileri bir araya getirir. Arama motoru ve gelişmiş filtre sistemiyle istediği alanla ilgili kanalları ve içerikleri sıralanmış şekilde görebilen kullanıcı tek tıkla videoyu izleyebilir, videonun ait olduğu kanala ulaşarak kişinin diğer içeriklerini görebilir. Kullanıcılar topluluklara ve istatistiklere ulaşabilir; trendler sekmesini kullanarak en çok izlenen ve en güncel videolara ulaşabilir. Bildirim özelliği açılarak takip edilen kanal video yüklediğinde anında haberdar olunur. İzleyici olmanın ötesinde kullanıcılar, içerik üreterek profilleri sayesinde ağa 
katkıda bulunabilir; izlenme, takip, beğeni ve yorum kriterleri göz önüne alınarak para kazanabilir. YouTube kullanıcıların sağladığı içeriklerle varlığının sürdüren bir sosyal alandır.

YouTube'un geri bildirim sağlama biçimleri beğeni butonu ve yorum bölümleridir. Kullanıcılar izledikleri videoları beğeni butonlarını kullanarak olumlu ya da olumsuz oylayabilmektedir. Bunun yanında üye olma şartıyla yorumlar kısmına kendi profili adı altında yorum yazabilir. Yakın zamanda tüm sosyal ağlarda öne çıkan ve sıkça kullanlan canlı yayın özelliği YouTube'da da aktif olmuştur. Bu sayede önceden çevrimiçi iletişimin kısıtlı olduğu bu alanda canlı yayın videosu altındaki sohbet bölümünden, kanal takipçisi olmayı gerektirmeden üye kullanıcılar tüm dünyadan insanlarla sohbete katılabilir. Seçim dönemlerinde partiler tarafindan sıkça kullanılan YouTube'un yoğun ilgi görmesiyle son dönemlerde politikacılar sıkça bu özelliği kullanmaktadır. Önceleri yalnızca televizyonlarda izleyebildiğimiz politik kişiler YouTube kanallarında canlı yayınlar açarak, şeffaflık isteğinin ön plana çıktığı son yıllarda talebi karşılama amacı gütmektedir. Örneğin belediye meclis toplantılarının yayınlanması ile bireyler yaşadığı şehre dair alınan kararlardan, geleneksel iletişim araçlarından yayınlanmasını beklemeden, anında haberdar olabilmiştir. Alınan kararlardan karar mercileriyle aynı anda haberdar olup beğeni ve yorumlar kısmından görüşlerini belirtme olanağı bulması demokratik gelişmelere sosyal ağların sağladığı önemli bir katkıdır.

Yelpazesi geniş bir video paylaşım ağı olan YouTube'da kullanıcılar, çok sayıda müzik videoları ve klipler, film ve belgeseller, eğitim ve bilim videoları, sohbet ve tartışma videoları gibi içeriklere ulaşabilir. Özellikle eğlence özelliği ön plana çıksa da bilim, spor, teknoloji, mühendislik, yazılım, kişisel gelişim gibi alanlarda da yoğun içeriklere sahiptir. Bireysel eğitim olanağı tanıyan bu alanlar özellikle yaşanan Koronavirüs salgınında dünya çapında kullanılarak insanların karantina sürecini evlerinde verimli geçirmelerini sağlamıştır.

Son yıllarda video blog anlamındaki "Vlog" içeriklerinin yaygınlaşması ile YouTube'a düzenli şekilde kendi yaşantısına dair videolar yükleyerek kendine takipçiler edinen kanallar yoğunlaşmıştır. Özellikle bu kanalların düzenli video yüklemeleri, izlenme oranlarının ve takipçi sayılarının yüksek olması hem YouTube'a hem de kanal sahibine yüksek kazançlar getirmiştir. "Youtuber", "vlogger" gibi isimlerle yeni sosyal medya meslekleri kazandırmıştır. Cep telefonu, tablet, bilgisayar, kamera gibi donanımların yaygınlaşıp gündelik hayatımızın ayrılmaz parçası haline gelişi, bunlara ulaşımın ucuz ve kolay olması video içerik üreticiliğinin yaygınlaşmasııın temel sebeplerindendir. Bunun yanında YouTube profillerinin ücretsiz ve kolay şekilde 
oluşturulabilmesi, sitenin basit bir arayüze sahip olması da yaygın şekilde kullanılmasının bir sebebidir.

YouTube'a yüklenen videolar dünyanın farklı yerlerinden; her sınıftan, dilden, dinden kişileri yansıtan içeriklere sahiptir. Birçok açıdan farklı kültürlere dair bilgiler içerir. Gelenek, görenek, değer ve düşünce sistemleriyle bir kültürün kendini ifade etmesine olanak tanır. Benzer özellikler gösteren kişiler bir araya gelebilmek için videolar etrafinda toplanmaktadır. Milyonlarca videoya ev sahipliği yapan sitede her kültür eşit şekilde içerik paylaşım ve erişim hakkına sahiptir. Dünyanın farklı köşelerinde yaşayan bireyler belki de hiç göremeyecekleri yerleri görüp, tanışamayacakları kişilerle tanışma firsatı bulur. Buna olanak sağlayan YouTube zengin görsel içerikler sunarak etkisini ve ilgi çekiciliğini arttırır.

\section{Amaç ve Yöntem}

Bir politik görüş olarak çokkültürlülük tanımının yanında dijital alandaki tanımının yapılabilmesini hedefleyen bu çalışmada amaç, dünya çapında en çok kullanılan sosyal ağlardan biri olan YouTube üzerinden örneklerle çokkültürlülüğe sağlanan katkının ortaya konmasıdır. Bu amaçla seçilen videolarda kanal sahibinin farklı kültürlere dair içerikleri incelenecektir.

Amaç doğrultusunda YouTube'da, farklı kültürden bir kullanıcının müzik videolarını izleyerek verdiği tepkileri içeren kanal ve bu kanaldan seçilen videolar derinlemesine olmada içerik analizi yöntemi kullanılarak incelenmiştir. İncelemenin sonucunda kanal sahibinin izlediği videolarda Türk kültürüne dair hangi içerikleri nasıl yansıttığı ortaya koymak hedeflenmiştir. Bu sayede sanal ortamda çokkültürlülüğe sağlanan katkılar ortaya konacaktır.

\section{Evren ve Örneklem}

Çokkültürlü yapının incelenmesi amacıyla yapılan çalışmada inceleme yapmak için dünyanın en büyük ve en çok kullanılan video paylaşım sitesi olan Youtube'dan yararlanılmıştır. "Reacting 
Video" adıyla birçok YouTube kanalında var olan tepki videoları içerikleri üreten bir kanal örneği seçilmesi amaçlanmıştır. Tepki videoları, kanal sahibinin aşina olmadığı bir kültüre dair müzik videoları, klipler, filmler, ünlü kişilere dair videoları ilk kez izleyip; yiyecek-içecekler, kıyafetler, enstrümanlar gibi kültürel öğeleri vb ilk kez deneyimleyerek verdiği tepkileri içerir.

Amaç doğrultusunda çalışmada "Kingdom of Luke" adlı, farklı kültürlere ait müzik videoları izleyerek tepki veren bir kanal incelenecektir. 2020 Temmuz ayı itibariyle 80 video sayısı bulunan kanalda Türkiye ile ilgili 54 video bulunmaktadır. (URL 2). Örneklem olarak videolar içinden Türk müziği içeriği olan 5 video seçilmiştir. "Zeki Müren-Elbet Bir Gün Buluşacağız Reaction”, "Haluk Levent-İzmir Marşı Reksiyon”, "Barış Manço-Dönence Tepki”, "Doğa İçin Çal 9-Hey Onbeşli Reaction", "Pentagram-Lions in a Cage Reaction" adlı videolar çalışmada incelenecek örnekler olarak seçilmiştir. Videolarda şarkı, şarkı türü ve şarkıcı hakkında bilgi, tarihsel bilgi, Türkçe kelime veya cümle kullanımı, kültüre dair yiyecek içecek, kültüre dair çıkarım, video altında Türkçe ve İngilizce yorum kullanımları aranacaktır. Ayrıca yorum sayısı, izlenme sayısı, olumlu/olumsuz beğeni sayısı belirtilecektir. Videolara dair bulgular ekteki tabloda görselleştirilmiştir.

\section{İnceleme}

\section{Kanal}

"Kingdom of Luke" adlı Youtube kanalı 27 Ekim 2019 tarihinde siteye katılmış ve 2020 y1lı Temmuz ayı itibariyle 70,900 aboneye sahip durumdadır. Tepki/reaksiyon konseptindeki kanal, açıldığı günden itibaren 9 milyon 53 bin 147 kez görüntülenmiştir. Temmuz ayı itibariyle kanalda 80 video bulunmaktadır. Birleşik Krallık menşeili kanalın içerik üreticisi bir İngilizdir.

Kanaldaki toplam 80 videodan 54'ü Türkiye ile ilgilidir. 54 videonun 52'si Türkiye'de mesleğini icra etmiş/etmekte olan ve Türkçe müzik yapan müzisyenlere aittir. İki video ise yine Türkiye ile ilgili içeriklere sahip videolardır. Videolardan biri Türkiye'yi tanıtan kısa bir videoya, diğeri ise Türkiye'yle özdeşleşmiş bir içkiyi ilk kez deneyimlediği tepki videosudur. Çalışmanın temeli olan 
52 müzik videosunun 18'i 'rock', 17'si 'rap', 5' 'halk müziği', 5'i 'pop', 4'ü 'arabesk', 2'si 'jaz/blues', 1'i ‘sanat müziği' türündedir.

Türk müzik videoları dışındaki 26 videodan 14'ü Kanada, 3'ü Nijerya, 3'ü Azerbaycan, 2'si Amerika, 2'si Kazakistan ve diğer 2'si Moğolistan ülkelerine ait müzisyenlere dair içeriklerdir. Yorumlar ve izlenme sayıları göstermektedir ki kanal takipçilerinin büyük bir bölümü Türkiyelidir. En çok izlenme sayısına sahip videolar Türk müziklerine ait videolardır (URL 3). İncelenen 5 Türk müzik videosundan 4'ünün sözleri Türkçe 1'i İngilizcedir.

\section{Videolar}

\section{Haluk Levent-İzmir Marşı Reksiyon}

Haluk Levent'in orkestra ve koro eşliğinde seslendirdiği İzmir Marşı, Kurtuluş Savaşı'nda Türk ordusunun İzmir'e girişini konu alır. Bu klibin izlendiği tepki videosunda kanal sahibi parça hakkında bilgi verir, bağımsızlık savaşında verilen mücadeleyi konu aldığını söyler. Parçanın türünün marş olduğunu belirtir. Bunun yanında parçayı seslendiren sanatçının rock müzik ile ilgilendiğine değinerek şarkıcı hakkında bilgi verir. Marşın, Kurtuluş Savaşında Türk ordusunun verdiği mücadeleyi anlatır. Bununla birlikte Atatürk’e değinerek Türk halkı ve ordusu için önemini anlatarak tarihsel bilgi verir. Anlatım sırasında "Kemal" ve "paşa" kelimelerini Türkçe telaffuz ederek bunların anlamlarını İngilizce olarak açıklar. Videonun sonunda edindiği izlenim ile Türk halkının vatanseverliği ve zaferlerinden gurur duyarak sonsuza dek yaşatma isteği içinde olduklarını söyler. İzleme deneyimi esnasında zafer duygusunu paylaştı̆̆ını ve askerlere saygı duyduğunu da belirterek Türkiye'ye dair çıkarım yapar. Videoda Türk külttürüne özgü yiyecek, içecek gibi kullanımlar yoktur. Videoda altında Türkçe ve İngilizce olmak üzere toplam 1719 yorum bulunmaktadır. Video 181.658 kere görüntülenmiş; 9.800+ olumlu, 81 olumsuz beğeni almıştır.

\section{Zeki Müren-Elbet Bir Gün Buluşacağız Reaction}

Türk sanat müziğinin en önemli isimlerinin başında gelen Zeki Müren'in seslendirdiği videoda, kanal sahibi şarkı ve şarkı türü hakkında bilgi vermezken şarkıcı hakkında bilgi verir. Zeki 
Müren'in hayatı, sanat dünyasındaki yeri, tarzı; şarkıcı, söz yazarı, besteci, şair, aktör, tasarımcı, terzi kimlikleriyle çok yönlü kişiliğine ve başarılarına dair detaylı bilgiler verir. Videoda Türk kültürüne dair bir tarihsel bilgi içeriği yoktur. Kanal sahibi video izleme deneyimi esnasında, Türkiye'de Zeki Müren'e karşı olan büyük saygıya dikkat çekmek için takım elbise giymiştir. Türkiye kültürüne özgü olan içki ve yiyecekleri deneyimler. "Afiyet olsun” cümlesini kullanırken, Türkçe olarak “zaman” kelimesini de kullanarak Ingilizce karşılığını belirtir. Türk müziğinin genel olarak duygu yüklü olduğunu, sözleri anlaşılmasa bile sanatçıların duyguyu dinleyicisine geçirdiğini söyleyerek kültüre dair çıkarımda bulunur. Video altında Türkçe ve İngilizce olarak 1853 yorum vardır. Video 94.576 kez görüntülenmiş; 5.900+ olumlu, 55 olumsuz beğeni almıştır.

\section{Barış Manço-Dönence Tepki}

Videoda şarkı ve şarkı türü hakkında bilgi vermez ancak şarkıcı hakkında detaylı bilgi verir. Türk müziğinin önemli isimlerinden biri olan Barış Manço'nun Türk kültüründeki önemine değinerek onun hayatı sanatı, çalışmaları hakkında bilgi verir. Seslendirilen parça hakkında tarihsel bilgi vermez. “Afiyet olsun” cümlesini söyler, “biliyorum” kelimesini telaffuz ederek İngilizce'deki karşılığını söyler. İzleme deneyimi esnasında Türk kültürüne dair yiyecek, içecek tüketmez. Barış Manço’yu uluslararası bir programda izlediğini, onun kültürünü tanıtmak için dünyayı gezdiği bilgisini vererek, onun Türkiye'nin vücut bulmuş hali olduğunu söyler. Bu sayede Türkiye hakkında çıkarımda bulunur. Video altında Türkçe ve İngilizce olarak 2370 yorum bulunur. Video 380.126 kere görüntülenmiş; 14.000+ olumlu, 373 olumsuz beğeni almıştır.

\section{Doğa İçin Çal 9-Hey Onbeşli Reaction}

Türk halk müziği örneği olan parçada içerik üreticisi şarkı sözlerinin İngilizce çevirisine bakarak şarkı hakkında bilgi verir. Bu şarkı türüne “türkü” denildiğini söyleyerek şarkı türü hakkında bilgi vermiş olur. Bir proje kapsamında birçok şarkıcı tarafından seslendirilen parçaların birleştirilmesiye ortaya çıkan parçanın bir proje çalışması olduğunu açıklayarak şarkıcı/proje sorumlusu hakkında bilgi verir. Türkünün sözlerinin hikayesini anlatarak Gelibolu Yarımadasında gerçekleşen Çanakkale Savaşı hakkında tarihsel bilgi verir. İzleme deneyimi esnasında kültüre dair yiyecek-içecek gibi farklı deneyimler yoktur. Türk kültürüne dair bir çıkarımda bulunmazken video altında Türkçe ve İngilizce olarak 785 yorum bulunmaktadır. Video toplamda $165.258 \mathrm{kez}$ izlenerek 5.700+ olumlu, 49 olumsuz beğeni almıştır. 
Pentagram-Lions in a Cage Reaction

Diğer parçalardan farklı olarak sözleri İngilizce olan parça, Türk metal müziğinin en önemli grubu Pentagram grubu tarafından seslendirilir. Kanal sahibi buna değinerek grup üyelerini tanıtır, şarkıcılar hakkında bilgi vermiş olur ancak şarkı türü hakkında bilgi vermez. Osmanlı İmparatorluğunun 25. Padişahı III. Osman'ın hikayesini anlattığını söyleyerek şarkı hakkında bilgi verir. III. Osman'ın elli bir yıl Topkapı Sarayı'nda hapsedilmesi olayını anlatarak tarihsel bilgi verir. "Çok teşekkürler” cümlesini Türkçe olarak telaffuz eder. İzleme deneyimi esnasında Türk kültürünün en önemli öğelerinden olan çayı içerek kültüre dair farklı bir deneyimde bulunur. Ancak kültüre dair bir çıkarımda bulunmaz. Video altında Türkçe ve İngilizce olarak 1005 yorum bulunur. Video 41.814 kere izlenerek; 2.100+ olumlu, 27 olumsuz beğeni almıştır.

\section{Bulgular ve Sonuç}

Günümüzde çok yönlü olarak ele alınan ve üzerinde sıkça konuşulan kültür kavramı insanoğlunun varlığıyla birlikte tohumlarını atmış, topluluklar halinde yaşayışı ile gelişme göstermiştir. Benzer davranış biçimleri, duygu ve düşünceleri paylaşan topluluklar arasında gelişen kültür, sonrasında insanlığın ayrılmaz parçası hatta kendisi haline gelmiştir. Toplumsal gelişimlere denk olarak 16. yüzyılda tarımsal faaliyetler kapsamında kullanılan kavram 18. yüzyıl sonrasında modernite ile yaşam biçimlerini ve zihinsel, manevi, estetik ve entelektüel süreçleri tanımlayan bir kavrama dönüşmüştür. Kavramsal olarak dönüşüme uğramasının sebebi küresel çapta yaşanan gelişimlerin ve etkileşimlerin bir sonucudur. Coğrafi keşiflere dayandırılan ancak esas olarak Sanayi Devrimi’nin getirdiği gelişmeler ile tam manasıyla yaşanan bir küreselleşme kavramına ulaşılmıştır. Uluslararası sınırların ortadan kalkmaya başlayıp ticari gelişmelerin yaşandığı dönemden günümüze geldiğinde ise küreselleşme sosyal, siyasal, toplumsal hatta bireysel her alanda yaşanmaktadır. Dünyamızın küresel bir köye dönüştüğü çağda, küreselleşme ile farklı kültürlerin dünyanın her alanına fiziksel ya da sanal olarak ulaşabildiği bir süreç yaşanmaktadır.

Küreselleşmenin getirdiği kavramlardan biri olan çokkültürlülük, kavramsal tartışma alanı olarak çok yeni olsa da tıpkı küreselleşme gibi insanlığın topluluklar halinde yaşamasıyla varlığı doğal olarak gelişen bir kavramdır. Çokkülürlülüğün kavramsal olarak ele alınışı, küreselleşmenin 
ekonomik, siyasi, sosyal her alanda dünyayı sararak kaçınılmaz bir sonuç olmasına dayanır. Farklı kültürlerden birçok insanın aynı ülke sınırları içinde yaşaması, her külttürün kendine özgü değerlerinin olması ve kişilerin bunları kendi özgürlük alanı içinde yaşamak istemesi hükumetleri arayışlara yöneltmiş̧ir. Bunun sonucu olarak çokkültürlülük kavramı önce Kanada'da başlayarak dünyanın farklı ülkelerine yayılmış farklı kültürlere dahil bireylerin kültürel özelliklerini koruyarak aynı zamanda birer dünya vatandaşı hissiyle yaşamalarını hedefleyen çokkültürcü politikaları doğurmuştur. Çokkültürlülük politik düzeyde tanımlanmanın yanında esas olarak toplumsal yapıyı tarif etmesi bakımından önemlidir. Nitekim bir toplumun çokkültürlü olması ile çokkültürcü politikalara sahip toplum aynı şeyi ifade etmez. Günümüz dünyasında toplulukların neredeyse hepsi çokkültürlüyken birçok ülke çokkültürcü politikaları tam anlamıyla uygulamaz. Teknolojik gelişmelerin sonucu olarak dijitalleşen dünyamızda çokkültürlülüğün toplumsal alanda yaşanmasının yanında bir de sanal ortamda, çok daha fazla kültürün katıldığı bir çokkültürlülükten bahsedilebilir. Çalışmanın konusu da dijital dünyada yaşanan çokkültürlülüğü örnekler üzerinden ortaya koymayı amaçlamıştır.

60'lı y1llarda politik korunma amalıyla geliştirilen ve sonrasında farklı kurul ve kuruluşların kullanımına açılan; yıllar içindeki gelişimiyle bugünkü anlamda internete ulaşan süreç günümüz toplum yapısını derinden etkileyen en önemli faktördür. Gelişiminin ilk yıllarında daha çok tek yönlü bir iletişim ortamı sağlayan internet sonraki dönemlerinde anlık iletişime firsat tanımıştır. Web 2.0 gelişiminin ortaya çıkardığı sosyal ağlar çevrimiçi, anlık etkileşimin gerçekleştiği ortamlar olarak karşımıza çıkar. Çalışmayı örneklendirmede ele aldığımız Youtube, dünyanın en büyük video paylaşım ortamı olarak dünya çapında birçok izleyiciye ulaşır. 2005'te kuruluşunun ardından ilgi gören YouTube yalnızca video paylaşma ve izleme platformu ötesinde profiller oluşturarak kişisel kanalların kurulmasına ve farklı alanların profiller etrafinda toplanmasına olanak sağlar. Kişiler, gelişmiş arayüzü sayesinde YouTube'da ilgi alanına yönelik videolara ve profillere ulaşabilir, ücretsiz olarak sınırsız izleme yapabilir, beğenisini dile getirip yorumlarda bulunabilir. Bunun yanında içeriğe katkıda bulunarak kanalında video paylaşırken; günümüzde geldiği nokta ile bir gelir kapısı olarak kullanılabilir. Tüm bu gelişmiş ve etkileyici özellikleri ile dünyanın farklı yerlerindeki kişilerin kolayca içeriğe katkı sağlamasına, kendini ifade etmesine olanak sağlarken izleyici olarak da farklı kültürlere dair içeriklere ulaşarak bunlar hakkında bilgi ve fikir sahibi olmaya olanak tanır. Yorum yazarak kültürel içerik hakkında görüşlerini paylaşabilir. 
İnceleme alanı olarak seçilen YouTube'un "Kingdom of Luke" kanalı farklı ülkelerin müzik kliplerini izleyerek farklı kültüre dair deneyimlerini ortaya koyar. İçerik oluştururken yalnızca izleme yapmak yerine izleyeceği video hakkında bir ön araştırma yapar. Örneklem olarak seçilen beş video ele alındığında videoların \%60'ında içeriği açıklayarak şarkı hakkında bilgi verir. Videoların \%40’ında şarkı türü hakkında bilgi verir. "Marş” ve "türkü” olarak kendine has özellikleri olan müzik türlerini açıklayarak özelliklerini belirtir. Kanal sahibi videoların \%100'ünde şarkıcılar hakkında bilgi verir. Şarkıcıların ne tür müzik yaptıklarını, hayatlarını, Türk müziğindeki yerlerini ve önemini açıklar. Bu sayede yabancı olduğu kültür hakkında sanatçılar üzerinden bilgi sahibi olmuş olur. Parçaların \%60'ında tarihsel bilgi verir. Bunların bir tanesi Osmanlı diğer ikisi I. Dünya Savaşı esnasında Türk halkının ve ordusunun yaşadığı mücadeleyi ele alır. Şarkı hakkında ön bilgi sahibi olan kanal sahibi, izleme deneyimi esnasında kendi gibi Türk kültürüne yabancı olan izleyiciler için, parçanın anlama kavuşabilmesi adına tarihsel bilgi verir. Bir kültürün anlaşılmasındaki en önemli noktalardan olan tarihsel bilgi böylece farklı kültürlere aktarılmış olur. Bunu bir diğer önemi de farklı kültür hakkında bilgilenen kişilerin neden sonuç ilişkisi ile dünya tarihi ve toplumsal düzenler hakkında çıkarım yapmasına olanak tanımasıdır. Anlamak, empati yapmanın ve farklılıklara saygı duymanın gerçekleşmesini sağlayarak çokkültürlü anlayışı geliştirir, kişilerin dünya vatandaşı olarak yetişmesine olanak sağlar.

Diğer bir değişken olan Türkçe kelime veya cümle kullanımını videoların \%100'ünde vardır. "Kemal, paşa, zaman, biliyorum" kelimelerini Türkçe telaffuz ederken bunların İngilizce karşılıklarını açıklaması içerik üreticisinin Türkçe kelimeleri öğrenerek kültür hakkında bilgi sahibi olmasını ve bunun diğer insanlarla paylaşmasını sağlamıştır. Aynı şekilde "afiyet olsun, çok teşekkürler" cümlelerini Türkçe telaffuzla yerinde kullanarak sözlü geleneklere dair bilgi ortaya koymuş olur. Videoların \%40'ında video izleme deneyimi esnasında Türk kültürü ile özdeşleşmiş içkiyi ve çayı tükettiği görülür. Türk kültürüne dair çeşitli değişkenlerle içerikler ortaya koyan İngiliz kanal sahibi diğer yandan farklı bir deneyimlemede bulunarak çayı bir İngiliz gibi değil Türkiye'de tüketildiği gibi demleyerek ve ince belli bardakta içmektedir. Bu da Türk kültürüne dair bilgi sahibi olduğu, dünyanın farklı yerlerinde farklı tüketim şekilleri olan çayın Türk kültüründe de kendine özgü bir kullanım şekli olduğunu takipçilerine göstermiş olur. 
Videoların \%60'ında kültüre dair çıkarımda bulunur. Bu videoların tamamı tarihsel içerikli sözleri olan parçalardır. İzleme deneyiminin sonucunda tarihsel içerikli parçalarda etkilendiğini, zafer ve mücadele duygusu paylaştığını belirtir. $\mathrm{Bu}$ da göstermektedir ki farklı toplumlar tarafından yaşansa da savaş, yıkım, zafer gibi durumlarda tüm dünya hakları ortak duygular geliştirebilir. Yine videoların \%100'ünde video altı yorumlarda Türkçe ve İngilizce yorumlar vardır. Bu da Türkiyeli kullanıcılar tarafından izlenmesinin yanında farklı kültürler tarafından izlendiğini ya da kullanıcıların tüm kültürlere hitap edebilmek için evrensel dil olan İngilizceyi kullandığının gösterir. Video içerikleri sayesinde farklı kültürden bir içerik üreticisi yabancı olduğu kültüre dair araştırmaları ve izlenimleri sonucu bilgi sahibi olmuş; bunları tüm dünyada en çok kullanılan video paylaşım sitesinde yayınlayarak milyonlarca insan tarafından ulaşılabilir hale getirmiştir. Birçok insan bu videoya ulaşma imkanı bulmuş, içeriği izleyenler Türk kültürü hakkında bilgi sahibi olma imkanı edinmiştir. Dijital alandaki çokkültürlü yapıya katkı sağlayan bu içerikler farklı kültürlerin birbiriyle empati kurabilmesine, kültür hakkında olumlu düşünceler geliştirmesine katkı sağlar; ırkçılığın, ayrımcılığın önüne geçilerek sevgi ve saygıyı ön plana çıkartır.

\section{Kaynakça}

Adıgüzel, M. (2011). Ekonomik, Kültürel ve Politik Küreselleşme ve Sonuçları. Ankara: Nobel Yayınlar1

Akyol, O. (2014). İnternet ve Değişen Televizyon Yayıncılı̆̆ı Teknolojileri. M. Aytekin (Ed.), Yeni(lenen) Medya (91-132). İstanbul: KOCAV Yayınları.

Aydeniz, N. ; Silinir, M. ; Karhan, G. (2012). Küreselleşme Olgusuna Temel Yaklaşımlar. Batman Üniversitesi Yaşam Bilimleri Dergisi. 1(1), s. 1013-1023

Aydoğan, F. (2011). Küresel Medya. İstanbul: Beta Yayınları 
Ay, A. (2017). $\quad$ Çokkültürlülük ve Kültürel Kimlik İnşası Bağlamında Türkiye’deki Çokkültürcü Medya Uygulaması: TRT Kurdi. (Doktora Tezi, İstanbul, Marmara Üniversitesi)

Çizmeci, E. (2014). Danah Boyd'da Sosyal Ağlar ve Gençlik. M. Çakır (Ed.), Yeni Medyaya Eleştirel Yaklaşımlar (385-411). İstanbul: Doğu Kitabevi.

Doytcheva, M. (2009). Çokkültürlülük. İstanbul: İletişim Yayıncılık.

Giddens, A. (1994). Modernliğin Sonuçları. İstanbul: Ayrıntı Yayınları

Güllüdağ, V. (2013). Postmodern İnşa Çerçevesinde Kültürel İnşa Dinamikleri: Youtube Örneği. (Yüksek Lisans Tezi, İzmir, Ege Üniversitesi)

Kara, T. (2013). Sosyal Medya Endüstrisi, İstanbul: Beta Yayınları

Kuyucu, M. ; Karahisar, T. (2013). Yeni İletişim Teknolojileri ve Yeni Medya.

İstanbul: Zinde Yayıncılık

Mahiroğulları, A. (2010). Küreselleşmenin Kültürel Değerler Üzerine Etkisi. Journal of Social Policy Conferences , 0 (50) , 1275-1288 . Retrieved from https://dergipark.org.tr/tr/pub/iusskd/ issue/891/9956 
Pieterse, J. N. (2006). Globalization as Hybridization. M.G. Durham, D.M. Kellner (Eds.), Media and Cultural Studies: KeyWorks (658-680). USA: Blackwell Publishing.

İnternet Kaynakları

URL 1 - https://sozluk.gov.tr/

URL 2 - https://www.youtube.com/c/KingdomOfLuke/playlists

URL 3 - https://www.youtube.com/c/KingdomOfLuke/featured 